\title{
Lexical Priming Effects of Textbooks on EFL Learners' Use of Give
}

\author{
Qi Xu ${ }^{1}$ \\ ${ }^{1}$ National Key Research Center for Linguistics and Applied Linguistics, Guangdong University of Foreign \\ Studies, Guangzhou, China \\ Correspondence: Qi Xu, National Key Research Center for Linguistics and Applied Linguistics, Guangdong \\ University of Foreign Studies, Guangzhou 510420, China. Tel: 86-138-2625-6962. E-mail: \\ xqmiracle@gmail.com
}

\author{
Received: August 16, 2015 Accepted: September 15, 2015 Online Published: September 16, 2015 \\ doi:10.5539/elt.v8n10p123 URL: http://dx.doi.org/10.5539/elt.v8n10p123
}

\begin{abstract}
The study aims to investigate to what extent Chinese EFL learners' language use is influenced by English textbooks. Such influence may suggest the existence of lexical priming effects. Based on detailed and systematic analysis of a learner English corpus, in comparison with a textbook corpus, the present study revealed striking similarities of the use of give ditransitive constructions between students' writing and the contents of textbooks. These similarities, at least to some extent, reflected lexical priming effects of English textbooks at the levels of colligations, collocates, and semantic associations. The study also offers suggestions for compilation of teaching materials and classroom teaching practice.
\end{abstract}

Keywords: lexical priming, textbooks, EFL learning, give ditransitives

\section{Introduction}

In the 2005 book of Lexical Priming, Hoey proposed the Lexical Priming theory, claiming that "every word is primed for use in discourse as a result of the cumulative effects of an individual's encounters with the word" (Hoey, 2005). To be more specific, the Lexical Priming accounts are stated as follows:

Whenever we encounter a word (or syllable or combination of words), we note subconsciously its collocations, colligations, semantic associations, pragmatic associations, textual collocations, the genre and/or style it is used in, etc. (Hoey, 2014)

This knowledge explains how speakers can use a language fluently, creatively, and naturally. For foreign language learners, especially learners at the initial stages, the major sources of lexical priming stem from language teaching materials. Previous literature (e.g., Elorza \& García-Riaza, 2010; Yang et al., 2000) has suggested that English textbooks exert potential influence on EFL learners' language use. Therefore, the study aims to compare language use in Chinese EFL learners' writing and English textbooks from the perspective of lexical priming.

The target structure of the study is the English ditransitive construction of the verb give. Give can occur in a variety of grammatical structures, but most interestingly, it can alternate between the ditransitive construction and the prepositional to-dative construction. For instance,

1) a Mary gave me a book. (ditransitive)

b Mary gave a book to me. (to-dative)

The investigation of the ditransitive verb give has been a topic of interest for a long time. A number of studies have focused on the use of give, for instance, Newman (1996), Mukherjee (2005), Bresnan and Hay (2008), Schilk et al. (2013), etc. It has been found that give is a high-frequency ditransitive verb. The major reason for the high frequency of give as a ditransitive verb is probably that the act of giving is considered as a "basic level category" (Newman, 1996), and give is a prototypical ditransitive verb in this category. However, most of previous studies only investigated native speakers' use of give. More research is needed to examine how give is used in learner English.

Through a contrastive analysis between a native English corpus and a learner corpus, Xu (2014) found that 
compared to native speakers and advanced learners, beginning learners show an item-based learning process, with great dependence on the ditransitive construction, frequent use of pronouns, and less various semantic classes. Since it has been suggested that English textbooks may pose a potential influencing source for learners' language use, it will be intriguing to investigate the extent to which EFL learners' use of ditransitve give is affected by English textbooks.

\section{Literature Review}

\subsection{Lexical Priming and Foreign Langauge Learning}

Hoey (2005) hypothesized that "lexical priming is the driving force behind language use, language structure, and language change". In his view, lexical priming can take place at various linguistic levels, including colligations, collocates, semantic associations, pragmatic associations, textual collocations, textual semantic associations, etc. The accounts lend much support to the importance of co-occurrence information surrounding a word. The lexical priming theory is based on the assumption that the particular use we make of a word is conditioned by our previous experience in our encounters with it in texts and communication. In this regard, the features of linguistic input for foreign language learners are extremely important.

In an instructional environment like China, middle school students are normally presented with such linguistic input that is "controlled and structured by the teacher... and by the materials used" (Gass, 1990). In another word, the major sources of lexical priming for beginning learners stem from classroom instructions and language teaching materials. It is inevitable that there may be some drawbacks using textbooks as the major source of input, since learners may receive classroom instructions and obtain input from exercises and exams. Nevertheless, with reference to the research carried out by $\mathrm{Xu}$ (2008), in middle schools, most classroom instructions given by the teacher were in Chinese and the exercises were primarily based on textbooks. Additionally, learners had little access to other sources of linguistic input than textbooks. Therefore, Chinese EFL learners at initial stages are greatly dependent on English textbooks.

Regretfully, many of the language teaching materials have provided learners with opportunities to encounter unhelpful lexical primings, such as overemphasis on certain kinds of language features, or on grammatical points.

Yang et al. (2000) investigated tense-aspect forms in English textbooks used in Hong Kong primary schools, and discovered the following characteristics:

- unbalanced distribution of different tense-aspect forms

- over-emphasis on basic interpersonal communicative skills and insufficient presentation of written language features

- $\quad$ lack of co-occurrence of different tense-aspect forms in the same texts

- unbalanced distribution of tense-aspect forms among verbs of different types.

By comparing English textbooks with Hong Kong students' written texts, Yang et al. (2000) detected similar problems in students' writing with those mirrored by textbooks. Their findings support the lexical priming effect of English textbooks on EFL learners' written production. However, the researchers failed to give sufficient explanations for the relationship between learners' language use and the contents of English textbooks.

Römer (2005) made a comparison between the use of progressives in native spoken English corpora (The British National Corpus and Bank of English) and in representations of spoken English used in German EFL textbooks. It was found that $30 \%-40 \%$ of progressives are used to indicate repeated actions or events in native corpora, while repeatedness is seldom expressed by progressives in textbooks, where more than $90 \%$ of the progressives refer to single continuous events, as in What are you doing? or What have you been doing? Römer (ibid: 284) cautions that "if we do not use more (real) examples which refer to repeated situations, learners might get the wrong impression that progressives can only be used to talk about single and not about multiple actions or events", and suggests that the function of repeatedness ought to be used more often in coursebooks especially with the verb forms such as coming, doing, helping, playing, etc.

To date, there is still a lack of research testing the effects of teaching materials on learner English. The present study will be a good contribution to this line of research. 


\subsection{Corpus-based Research on Lexical Priming}

With regard to investigations of the lexical priming accounts, corpus has been proved as a useful tool for lexical priming research. As Hoey (2005) indicates, although corpus does not directly present information of lexical priming, it can provide data that a person may encounter when being primed, and suggest what kinds of features of words or word sequences may be primed. That is to say, corpus can be used to testify claims made about lexical priming.

In child language acquisition, adult language that is spoken to children is often regarded as the major input source for children (Yip \& Matthews, 2007). Chan (2010) analysed the input data from The Hong Kong Bilingual Child Language Corpus (Yip \& Matthews, 2007) and The Hong Kong Cantonese Child Language Corpus (Lee \& Wong, 1998), and evaluated the role of input in bilingual children's acquisition of the Cantonese double object construction with bei2 'give'. Chan found that the inconsistency of input (for example, different word orders for the double object construction between Cantonese and English) contributes to bilingual children's vulnerability in learning this grammatical structure. The findings, to a certain extent, reflected the lexical priming effect of direct speech given to children on first language acquisition.

From the perspective of lexical priming, Yang and Yang (2010) compared the use of the lexical bundle more and more between The Chinese Learner English Corpus (CLEC) and The British National Corpus (BNC). They found that native speakers tend to use more and more less frequently than Chinese EFL learners, but with more varieties in terms of grammatical constructions, semantic collocation, and pragmatic functions. In addition, lexical priming from L1 Chinese was detected based on the fact that the Chinese equivalent of more and more is a frequently used formulaic sequence. It was thus suggested that both teachers and learners should make good use of linguistic resources like corpus and be aware of frequency distributions in English language use.

Xu (2014), through comparing CLEC and LOCNESS (The Louvain Corpus of Native English Essays), found that beginning learners perform quite differently from native speakers of English in terms of the verb give. The findings show that beginners rely heavily on ditransitive constructions $(50.4 \%)$ among all the grammatical structures. With regard to ditransitive give, they frequently use pronouns as indirect objects $(84.3 \%)$ and have a great preference of Transfer (39.5\%) and Communication (17.4\%) as major semantic classes. In stark contrast, native speakers use ditransitive constructions less frequently (34\%), use fewer pronouns $(45.8 \%)$, and prefer such semantic classes as Permission (37.3\%) and Enablement (34\%).

On the basis of previous literature, the present study incorporates corpus tools in examination of lexical priming effects, aiming to answer the research question: To what extent do lexical priming effects of English textbooks occur in Chinese EFL learners' use of give ditransitive constructions?

\section{Method}

\subsection{Corpora}

The learner corpus adopted in the study is The Chinese Learner English Corpus (CLEC), which was released in 1998 in mainland China (Gui \& Yang, 2002). It contains one-million-word essays written by Chinese learners at five different educational levels. The sub-corpus of the beginning-level learners, i.e. senior middle school students (ST2), was selected for comparison with textbooks. The size of CLEC_ST2 is 208,088 words.

With regard to the textbook corpus, it consists of two series of English textbooks, i.e. Junior English for China and Senior English for China published by People's Education Press (1996 version), with a size of approximately 207,000 words. Junior English for China was widely used in junior middle schools, and Senior English for China in senior middle schools. The major reason of choosing these two series of textbooks is that Junior English for China (first published in 1993 and received minor revisions in 1996) had been used by senior middle school students in CLEC_ST2 and Senior English for China was being used (published in 1996) while CLEC was compiled in 1998. Therefore, the textbook corpus can basically represent the input sources of the participants of CLEC_ST2.

\subsection{Data Extraction}

A corpus search was first conducted in CLEC_ST2 to extract ditransitive constructions of the verb give, and then in the textbook corpus. The extraction tool used was WordSmith 5.0. Since neither CLEC_ST2 nor the textbook corpus has been syntactically parsed, manual analysis was conducted afterwards. Given that similar procedures were used to extract data from both corpora, I will mainly demonstrate how to retrieve ditransitive constructions 


\section{in CLEC_ST2.}

First, all the texts in CLEC_ST2 were selected in WordSmith 5.0 for data extraction. Then in the Concord window, a new search was established by typing in different forms of give, namely, simple present, third person present singular, simple past, past participle and the -ing form (i.e. 'give/gives/gave/given/giving'). After pressing 'OK', all the instances that contain various forms of give appeared automatically in a separate concord window. The retrieved concordances were saved in an Excel spreadsheet to facilitate further analysis. Similar procedures were carried out in the textbook corpus. As a matter of fact, data extracted at this stage include all kinds of transitivity types of the verb. Therefore, further analysis should be made in terms of ditransitivity.

\subsection{Data Analysis}

During the process of data analysis, the first step was conducting manual analysis to categorize all the grammatical structures where give has occurred, such as monotransitive, ditransitive, to-dative, etc. Then focus was put on the ditransitive construction of give, with an examination of the variables of pronominality and semantic classes. Based on Hoey (2005: 13), these variables can well complement each other by testing different aspects of lexical priming effects. Different grammatical structures that give can occur in correspond to the level of colligations, pronominality to collocates, and semantic classes to semantic associations.

- Grammatical structures: Every word is primed to occur in (or avoid) certain grammatical positions, and to occur in (or avoid) certain grammatical functions; these are its colligations.

- Pronominality: Every word is primed to occur with particular other words; these are its collocates.

- Semantic classes: Every word is primed to occur with particular semantic sets; these are its semantic associations.

The major grammatical structures that allow the occurrence of give are listed below with corresponding examples (IO represents indirect object, DO direct object, and PC prepositional complement).

\section{Construction}

ditransitive

to-dative

monotransitive

phrasal verb

$$
\begin{aligned}
& \text { Structure } \\
& \text { give + } \mathrm{IO}+\mathrm{DO} \\
& \text { give + DO + to + PC } \\
& \text { give + DO } \\
& \text { give + particle }
\end{aligned}
$$

\section{Example}

Mary gave me a book.

Mary gave a book to me.

Mary gave a report yesterday.

Mary finally gave up.

Pronominality is defined "to distinguish phrases headed by pronouns (personal, demonstrative, and indefinite) from those headed by non-pronouns such as nouns and gerunds" (Bresnan et al., 2007). In this study, analysis of pronominality is quite straightforward. IO and DO in the ditransitive construction were analysed for pronominality, i.e. whether it is a pronoun or not.

Regarding semantic classes, Newman (1996) classified the meanings of give into literal and figurative usages. Literal give refers to "the transfer of some concrete object from one person to another" (ibid.: 133), while figural give involves a range of additional meanings which are extensions from the sense of 'transfer' within the framework of cognitive linguistics. A list of the major categories of figurative extensions was provided in Newman (1996), including interpersonal communication, causation, enablement, permission, schematic interaction, etc. Based on Newman's classification, Table 1 summarizes the eight semantic classes of the ditransitive give in the study, together with their specific meanings and examples. 
Table 1. Semantic classes of give in the study

\begin{tabular}{|c|c|c|}
\hline Semantic class & Specification & Example \\
\hline Transfer & Transfer of ownership of concrete things & give someone a book \\
\hline Communication & $\begin{array}{l}\text { Communicative acts between people (or } \\
\text { person-like entities) }\end{array}$ & give someone advice \\
\hline Permission & $\begin{array}{l}\text { Enabling the permittee to act in some way } \\
\text { through exercising some authority, }\end{array}$ & give someone the right(s) \\
\hline Enablement & Causation of a potential for some event & give someone insight \\
\hline Causation & $\begin{array}{l}\text { Causing someone to have problems; } \\
\text { Having someone do something }\end{array}$ & $\begin{array}{l}\text { give someone trouble } \\
\text { give someone homework }\end{array}$ \\
\hline Feeling & Making someone have a feeling & give someone confidence \\
\hline Schematic interaction & $\begin{array}{l}\text { Association with a schematic meaning } \\
\text { which combines with the deverbal } \\
\text { predicate }\end{array}$ & give someone a kiss \\
\hline Idiom & Formulaic expressions & give someone an impression \\
\hline
\end{tabular}

\section{Results}

The corpus research reveals the following features of ditransitive give used in CLEC_ST2 and textbooks.

4.1 Grammatical Structures

Table 2 compares the proportions of each give-structure in CLEC_ST2 and the textbook corpus.

Table 2. Proportions and frequencies of give-patterns in both corpora

\begin{tabular}{lllll}
\hline Constructions & \multicolumn{3}{l}{ CLEC_ST2 } & \multicolumn{2}{l}{ Textbook corpus } \\
\cline { 2 - 5 } & $\%$ & (Freq.) & $\%$ & (Freq.) \\
\hline Ditransitive & $50.4 \%$ & $(172)$ & $45 \%$ & $(106)$ \\
To-dative & $14.7 \%$ & $(50)$ & $11 \%$ & $(26)$ \\
Monotransitive & $15 \%$ & $(51)$ & $21.6 \%$ & $(51)$ \\
Phrasal verb & $14.4 \%$ & $(49)$ & $14 \%$ & $(33)$ \\
Passive ditransitive & $2.6 \%$ & $(9)$ & $5.5 \%$ & $(13)$ \\
Passive to-dative & $0.3 \%$ & $(1)$ & $3 \%$ & $(7)$ \\
Idiosyncratic use & $2.6 \%$ & $(9)$ & $0.0 \%$ & $(0)$ \\
Total & $100 \%$ & $(341)$ & $100 \%$ & $(236)$ \\
\hline
\end{tabular}

It is shown in Table 2 that give is most frequently co-ocurring with the ditransitive construction in both corpora. Slight differnces lie in that ditransitive and to-dative constructions are used relatively more frequently in CLEC_ST2 than in the textbook corpus, while monotransitives and passive ditransitives are more frequent in the textbook corpus.

These various grammatical structures are well illustrated with the following examples.

2) Because sometimes I have no faith for my study, it gives me the courage. (Ditransitive) $<$ CLEC_ST2 $>$

3) On spring festival, the older give 'lucky money' to the younger. (To-dative) $<$ CLEC_ST2 $>$

4) Many offices use answering machines to give information. (Monotransitive) $<$ Textbook corpus $>$

5) King called for black people not to give in but to continue the struggle. (Phrasal verb) $<$ Textbook corpus $>$ 
6) Each group was given some pork, some chicken, some eggs and some vegetables and any kitchen-wares. (Passive ditransitive) $<$ CLEC_ST2 $>$

7) One half of his money and his goods shall be given to the city of Venice. (Passive to-dative) $<$ Textbook corpus $>$

8) (?) In my opinion, I think the two-days weekend is good, it can help me to finish the homework and the housework, it can give me to have a rest, it can make me do a lot of things. (Idiosyncratic use) $<$ CLEC_ST2) $>$

\subsection{Pronominality}

Table 3 presents a sharp contrast of pronominality between the realizations of IO and DO in ditransitive constructions. IO is more frequently realized by pronouns, while DO is realized by noun phrases in both corpora. In previous research $(\mathrm{Xu}, 2014)$, it has been found that beginners tend to rely on pronouns as realizations of indirect object. A comparison with the textbook corpus indicates that pronouns are also frequently used after the verb give in textbooks (75.5\%), although less often than in CLEC_ST2 (84.3\%).

Table 3. Pronominality of objects in ditransitive constructions

\begin{tabular}{llllll}
\hline \multirow{2}{*}{ Object } & Pronominality & \multicolumn{3}{l}{ CLEC_ST2 } & \multicolumn{2}{l}{ Textbook corpus } \\
\cline { 3 - 6 } & & $\%$ & (freq.) & $\%$ & (freq.) \\
\hline IO & Pronoun & $84.3 \%$ & $(145)$ & $75.5 \%$ & $(80)$ \\
& NP & $15.7 \%$ & $(27)$ & $24.5 \%$ & $(26)$ \\
\multirow{2}{*}{ DO } & Pronoun & $1.2 \%$ & $(2)$ & $2 \%$ & $(2)$ \\
& NP & $98.8 \%$ & $(170)$ & $98 \%$ & $(104)$ \\
\hline
\end{tabular}

The high frequency of pronoun use may be under the influence of the text types in CLEC_ST2 and the textbook corpus. The texts in both corpora mainly consist of narrations and descriptions, which are more likely to prompt the use of personal pronouns. Below are some example sentences.

9) She gave me two present on my birthday. $<$ CLEC_ST2 $>$

10) They have to give us a talk about the zoo next month. $<$ CLEC_ST2 $>$

11) Mrs. King asked me to give you this note. $<$ Textbook corpus $>$

12) Did you give our English teacher a card for Teachers' Day? < Textbook corpus $>$

\subsection{Semantic classes}

With regard to semantic classes, previous research found that beginning learners prefer to use concrete senses such as Transfer and Communication, instead of abstract senses such as Enablement and Permission.

Table 4 shows that Transfer and Communication are the two most favored semantic classes shared by two corpora. In particular, the textbook corpus is primarily restricted to the use of Transfer (54.7\%) and Communication (32.1\%). By contrast, other semantic classes are used less frequently in both corpora. Newman (1996: 2-3) considers the act of giving, especially giving "concrete, easily visualizable entities", as a "basic level category", and this level was said to be learned earliest. To be more specific, transfer of objects requires less cognitive processing, thus making it easier for beginning learners to learn. It is therefore not surprising to see give more frequently used in the sense of Transfer by beginners and low-level textbooks. In comparison, the senses of Enablement and Permission are relatively more abstract, and require higher language proficiency. 
Table 4. Proportions and frequencies of different semantic classes of ditransitive give in both corpora

\begin{tabular}{lllll}
\hline Constructions & \multicolumn{3}{l}{ CLEC_ST2 } & \multicolumn{2}{l}{ Textbook corpus } \\
\cline { 2 - 5 } & $\%$ & $($ Freq.) & $\%$ & (Freq.) \\
\hline Transfer & $39.5 \%$ & $(68)$ & $54.7 \%$ & $(58)$ \\
Communication & $17.4 \%$ & $(30)$ & $32.1 \%$ & $(34)$ \\
Enablement & $11.0 \%$ & $(19)$ & $5.7 \%$ & $(6)$ \\
Permission & $3.5 \%$ & $(6)$ & $2.8 \%$ & $(3)$ \\
Causation & $3.5 \%$ & $(6)$ & $2.8 \%$ & $(3)$ \\
Schematic & $6.4 \%$ & $(11)$ & $1.9 \%$ & $(2)$ \\
Feeling & $9.3 \%$ & $(16)$ & $0.0 \%$ & $(0)$ \\
Idiom & $1.2 \%$ & $(2)$ & $0.0 \%$ & $(0)$ \\
Idiosyncratic usage & $8.1 \%$ & $(14)$ & $0.0 \%$ & $(0)$ \\
Total & $100 \%$ & $(172)$ & $100 \%$ & $(106)$ \\
\hline
\end{tabular}

What should be noted is that under the influence of different topics and based on their writing needs, beginners' use also covers the senses that are of low frequency in textbooks, for instance, Schematic interaction and Feeling. This suggests lexical priming is also sensitive to the contexts (textual, generic, social) in which the lexical item is encountered. Contexts are important in that only with contexts will the word be appropriately primed (Hoey, 2005). Sentences 13-19 are some examples of different semantic classes.

13) She gave me two pens on my birthday. (Transfer) $<$ CLEC_ST2 $>$

14) I give her some bird food every day. (Transfer) $<$ Textbook corpus $>$

15) She gave me some advice on how to learn the foreign language, English. (Communication) $<$ CLEC_ST2 $>$

16) Miss Zhao asked Jim to give the class a talk. (Communication) <Textbook corpus $>$

17) Here she did everything, from washing floors to giving sick people new hope. (Enablement) $<$ Textbook corpus $>$

18) Though I know the final is nothing with me, I (was) glad to join in the match, because it gave me a chance to practise. (Permission) <CLEC_ST2>

19) They thanked us for supporting their education and giving them so much happiness. (Feeling) $<$ CLEC_ST2 $>$

Additionally, a number of idiosyncratic usages were detected from the beginner corpus (14 instances in give ditransitive constructions). One commonality shared by these idiosyncratic cases is that the ditransitive constructions are syntactically correct, but semantically inappropriate in English. They seem to be direct traslations from Chinese meanings. Sentences 20-22 are some examples of idiosyncratic usages by beginning learners.

20) (?) The new playground gave me a new looking

21) (?) Get up early can give you a good habit.

22) (?) If you want to talk with me, then I will give some face to you.

\section{Discussion}

It is undeniable that there are a variety of influencing factors on Chinese EFL learners' use of the ditransitive verb give, such as L1 influence, classroom teaching, text type, learners' developmental stages, etc. However, the primary goal of the current study is to explore the potential effect of English textbooks. An examination of the beginning learner corpus and the English textbooks data suggests the possibility of lexical priming effects of textbooks on foreign language learning of give ditransitive constructions. By means of three variables (grammatical structures, pronominality, and semantic classes), the present study found different levels of lexical 
priming, i.e. colligations, collocates, and semantic associations. In a foreign language learning environment like China and many other coutnries in the world, beginning EFL learners' encounters with English language mostly come from English textbooks. Findings in the study, at least to some extent, support the lexical priming effect of English textbooks on learners' use of give, although no clear-cut one-to-one correspondence was detected.

The study provides implications for teaching materials compilation. Based on descriptions of the contents of English textbooks (version in 1996) given by Adamson (2004), a large number of texts included are anecdotes and stories. These two text types mainly reflect spoken language features, rather than written language.

A major consequence of the narrow range of text types is that learners have little access to other registers of writing, and there is less possibility for them to be aware of genre differences in writing. This, to a certain extent, explains the speech-like features in Chinese EFL learner's writing, for example, frequent use of personal pronouns. It is therefore suggested that an increasingly diversified variety of registers should be included in textbooks at higher educational levels. Teachers are also encouraged to provide learners with supplementary readings of different genres/registers.

Another consequence of textbooks' focus on anecdotes and stories is the limitations in semantic usages of verbs. It has been found that the use of give in English textbooks mainly involves senses of Transfer and Communication, with a lack of semantic categories at a more abstract level (for example, Enablement and Permission). It is important to gradually enlarge the vocabulary size, but what is equally important is to enrich varied usages of basic verbs like give.

This corpus-based research also provides valuable insights for classroom teaching. As far as foreign language teaching is concerned, we should be wary of the lexical priming of learners' first language. Unlike first language acquisition where children acquire their first language in naturalistic environments, L2 learners are mostly confined to classroom settings which can, to some extent, distort the input patterns (Ellis \& Laporte, 1997). Exposure to the target language is normally far from sufficient for L2 learners to override the influence from their mother tongue. Evidence of L1 influence has also been discovered in the study, for instance, learners' idiosyncratic usages of semantic classes. Once given a single word translation of an item to be learnt in the foreign language, the learner will easily and immediately activate the lexical primings from the first language. The danger lies in that learners are not able to distinguish words that bear the same meaning in two languages but differ greatly in terms of lexical primings for L1 speakers regarding collocations, colligations, and semantic associations. Therefore, what EFL teachers should do is reduce L1 effect to the maximum degree, rather than enlarge its influences.

In traditional teaching of a verb, for instance, teachers usually first teach how to spell and pronounce it, and then explain its equivalent meaning in Chinese. What is worse, teachers also translate the example sentences into Chinese. This will strengthen the association between the English word and its Chinese meaning and usage. Teaching words in isolation is not effective enough for students to apply them into practical use. It is therefore suggested by Hoey (2005) that foreign language learners "should be exposed to authentic data wherever possible, and the data should both reinforce existing priming (i.e. by overlapping with previously encountered material) and permit new priming to take place".

Among various methodologies, concordance-based exercises have been proved to be an effective complement to traditional teaching strategies (Granger, 2002, 2009; Meunier 2002). As suggested by Römer (2009), "corpora and concordance packages present very useful resources for the creation of exercises that motivate the learner and promote her/his language awareness".

Based on detailed and systematic analysis of learner English, in comparison with the textbook corpus, the present study has provided implications from both theoretical and pedagogical perspectives. It presents evidence for the potential lexical priming effect of textbooks on EFL learners' language use, and also gives specific suggestions for compilation of teaching materials and classroom teaching practice. For future research, it will be worth the effort exploring the textbooks' potential effect of lexical priming on learners' use of other grammatical structures.

\section{Acknowledgements}

The study is supported by Innovative School Project in Higher Education of Guangdong, China (GWTP-BS-2015-20). I would like to thank Professor Gerald Nelson for his insightful guidance and the anonymous reviewers for their invaluable comments and suggestions. 


\section{References}

Adamson, B. (2004). China's English: A History of English in Chinese Education. Hong Kong: Hong Kong University Press.

Bresnan, J., Cueni, A., Nikitina, T., \& Baayen, R. H. (2007). Predicting the dative alternation. In G. Boume, I. Kraemer, \& J. Zwarts (Eds.), Cognitive Foundations of Interpretation. Amsterdam: Royal Netherlands Academy of Science.

Bresnan, J., \& Hay, J. (2008). Gradient grammar: An effect of animacy on the syntax of give in New Zealand and American English. Lingua, 118(2), 245-259. http://dx.doi.org/10.1016/j.lingua.2007.02.007

Chan, A. (2010). The Cantonese double object construction with bei2 'give' in bilingual children: The role of input. International Journal of Bilingualism, 14(1), 65-85. http://ijb.sagepub.com/content/14/1/65

Ellis, N. C., \& Laporte, N. (1997). Contexts of acquisition: Effects of formal instruction and naturalistic exposure on second language acquisition. In A. M. B. de Groot, \& J. F. Kroll (Eds.), Tutorials in Bilingualism: Psycholinguistic Perspective (pp. 53-83). Hillsdale, NJ: Lawrence Erlbaum.

Elorza, I., \& García-Riaza, B. (2010). FL students' input in higher education courses: Corpus methodology for implementing language representativeness. In M. C. Campoy-Cubillo, B. Bellés-Fortuño, \& M. L. Gea-Valor (Eds.), Corpus-Based Approaches to English Language Teaching (pp. 216-229). London: Continuum.

Gass, S. M. (1990). Second and foreign language learning: Same, different or none of the above? In B. Van Patten, \& J. F. Lee (Eds.), Second Language Acquisition - Foreign Language Learning (pp. 34-44). Clevendon: Multilingual Matters.

Granger, S. (2002). A bird's-eye view of learner corpus research. In S. Granger, J. Hung and S. Petch-Tyson (Eds.), Computer Learner Corpora, Second Language Acquisition and Foreign Language Teaching (pp. 3-36). Amsterdam: John Benjamins.

Granger, S. (2009). The contribution of learner corpora to second language acquisition and foreign language teaching: A critical evaluation. In A. Karin (Ed.), Corpora and Language Teaching. Amsterdam: John Benjamins.

Gui, S. and Yang, H. (2002). Chinese Learner English Corpus. Shanghai: Shanghai Foreign Language Education Press.

Hoey, M. (2005). Lexical Priming: A New Theory of Words and Language. London: Routledge.

Hoey, M. (2014). Old approaches, new perspectives: the implications of a corpus linguistic theory for learning the English language. Plenary session, 48th Annual International IATEFL Conference, Harrogate, 4 April. Available at http://iatefl.britishcouncil.org/2014/sessions/2014-04-04/plenary-session-michael-hoey (accessed on 10 August 2014).

Lee, T., \& Wong, C. (1998). CANCORP: The Hong Kong Cantonese Child Language Corpus. Cahiers de Linguistique d'Asie Orientale, 27, 211-228.

Meunier, F. (2002). The pedagogical value of native and learner corpora in EFL grammar teaching. In S. Granger, J. Hung, \& S. Petch-Tyson (Eds.). Computer Learner Corpora, Second Language Acquisition and Foreign Language Teaching. Amsterdam/Philadelphia: John Benjamins.

Mukherjee, J. (2005). English Ditransitive Verbs: Aspects of Theory, Description and a Usage-based Model. Amsterdam/New York: Rodopi.

Newman, J. (1996). GIVE: A Cognitive Linguistic Study. Berlin/New York: Mouton de Gruyter.

Römer, U. (2005). Progressives, Patterns, Pedagogy: A Corpus-Driven Approach to Progressive Forms, Functions, Contexts and Didactics. Amsterdam: John Benjamins.

Römer, U. (2009). Corpus research and practice: What help do teachers need and what can we offer? In K. Aijmer (Ed.), Corpora and Language Teaching. Amsterdam/Philadelphia: John Benjamins.

Schilk, M., Mukherjee, J., Nam, C., \& Mukherjee, S. (2013). Complementation of ditransitive verbs in South Asian Englishes: A multifactorial analysis. Corpus Linguistics and Linguistic Theory, 9(1), 1-38. http://dx.doi.org/10.1515/cllt-2013-0001 
Xu, Q. (2008). A Study of Middle School English Teaching Reform in China. Unpublished BA Thesis, Shandong University, Weihai.

Xu, Q. (2014). A Corpus-based Study of Alternating Ditransitive Constructions in Chinese Learner English. Unpublished PhD Thesis, The Chinese University of Hong Kong, Hong Kong.

Yang, S., Huang, Y., \& Lee, N. (2000). Some reflections on English textbook input for Hong Kong students Based on a case study of tense-aspect acquisition problems. Asia Pacific Journal of Language in Education, $3(1), 1-24$.

Yang, Y., \& Yang, Y. (2010). Schematic construction as reflected in lexical priming with Chinese learners of English: The case of more and more. Foreign Language Learning Theory and Practice, 2, 36-43.

Yip, V., \& Matthews, S. (2007). The Bilingual Child: Early Development and Language Contact. Cambridge: Cambridge University Press.

\section{Copyrights}

Copyright for this article is retained by the author(s), with first publication rights granted to the journal.

This is an open-access article distributed under the terms and conditions of the Creative Commons Attribution license (http://creativecommons.org/licenses/by/3.0/). 